\title{
A erística no ensino de ciência
}

\author{
Elivane Amaral de Souza Assis ${ }^{1}$ \\ elivaneamaral@hotmail.com
}

\section{Fábio Wellington Orlando da Silva ${ }^{2}$ fabio@des.cefetmg.br}

\section{Resumo}

Esta pesquisa investiga a habilidade dos estudantes de nível superior para reconhecer argumentos falaciosos, detectando afirmações inválidas apresentadas em textos pseudocientíficos, e para compreender o processo de construção da ciência como algo rico e criativo, diferentemente de meras conclusões presentes em livros didáticos. A metodologia de pesquisa é baseada em estudo de caso, envolvendo estudantes de ciências exatas ehumanas, aos quais foi distribuído um texto pseudocientífico para análise. Nenhum estudante foi capaz de detectar os estratagemas inválidos contidos no texto, apesar de alguns perceberem certos exageros. Recomenda-se aliar o ensino de filosofia ao de ciência - particularmente a utilização da Erística deSchopenhauer - para desenvolver a habilidade dos estudantes em reconhecer argumentos falaciosos.

Palavras-chave: Erística; ensino de ciências; maiêutica.

\section{Introdução}

O objetivo desta pesquisa é investigar a habilidade dos estudantes de nível superior de áreas científico-tecnológicas para reconhecer argumentação falaciosa que se apresenta em diversas mídias como discurso científico autêntico, mas em verdade consti-

\footnotetext{
${ }^{1}$ Professora da Faculdade de Educação - Campus Belo Horizonte - Universidade do Estado de Minas Gerais (FaE/CBH/UEMG). Mestre em Educação Tecnológica, membro do grupo de pesquisa Ficitec.

${ }^{2}$ Professor do Centro Federal de Educação Tecnológica de Minas Gerais (Cefet/MG). Doutor em Física, membro do grupo de pesquisa Ficitec.
}

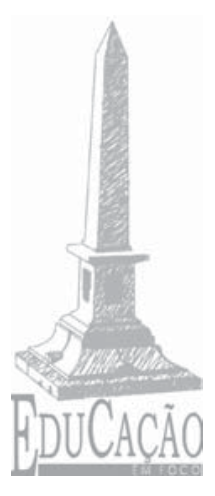

67

Ano 12 - n. 14 - dezembro 2009 - p. 67-81 
tui, no caso mais favorável, apenas uma manifestação pseudocientífica.

A estratégia de pesquisa é a de estudo de caso (YIN, 2010), porque uma de suas características é a possibilidade de coletar informações específicas e detalhadas, frequentemente de natureza pessoal, envolvendo o pesquisador com um grupo de indivíduos em uma determinada situação e durante um dado intervalo de tempo.

Os estudantes receberam um texto pseudocientífico típico e responderam a um questionário de avaliação. $\mathrm{O}$ texto e as respostas obtidas foram analisados com base nas categorias elaboradas por Arthur Schopenhauer (1788-1860), constituídas por 38 estratagemas, globalmente designados por Dialética Erística ou simplesmente Erística. Esses estratagemas são regras inválidas de argumentação, habitualmente empregadas para vencer um debate a qualquer custo, confundindo e desmoralizando o adversário (SCHOPENHAUER, 2005). Nesse caso, porém, elas foram usadas para reconhecer e ensinar a desmontar as artimanhas presentes nesse tipo de debate.

A relevância deste trabalho para a área de ensino/educação refere-se à necessidade de detectar falhas na formação dos profissionais de nível superior, inclusive de professores, cujo aprimoramento é imprescindível para elevar o padrão de ensino nas escolas. É fundamental que eles tenham conhecimento da epistemologia da ciência, permitindo-lhes a compreensão de suas estruturas, bem como do espaço que ocupa no sistema intelectual.

Conferências internacionais, artigos e livros publicados a partir de 1989 mostram o interesse cada vez maior por essa temática. Pesquisas realizadas no Brasil e no exterior revelam que diversos professores vêm encorajando seus alunos a conduzir "diálogos socráticos", como forma de desenvolver a capacidade de elaborar questões e de reconhecer incoerências argumentativas. Wenning (2006) é um dos autores que utilizam tais diálogos. Segundo ele, os alunos estão sempre envolvidos em discussões nas salas de aula, mas geralmente só apresentam uma atitude responsiva e não fazem perguntas apropriadas. Por isso, recomenda que os professo- 
res desenvolvam nos estudantes "a disposição e habilidade" para fazer perguntas adequadas.

O método presente nos diálogos de Sócrates foi desenvolvido por esse filósofo grego do século V a.C. e inaugura o chamado período antropológico da filosofia grega (MONDOLFO, 1972). Sócrates (apud PLATÃO, 2007) fazia uma analogia entre o trabalho de sua mãe e o seu. Ele dizia que ela era parteira de mulheres e trazia ao mundo crianças; ele era parteiro de homens, trazia ao mundo ideias através do diálogo como modo de parturição. Isso significa que ele ensinava aos indivíduos, através do diálogo, a arte de raciocinar de modo adequado, fazendo-lhes perguntas, estabelecendo relações entre as ideias, detectando contradições ocultas e desvelando consequências para chegar a conclusões verdadeiras.

A finalidade desse método é de natureza ética e educativa (JAEGER, 2003) e pode ser dividido em: a) exortação; b) refutação; c) maiêutica. A "exortação" é o ponto de partida em que Sócrates exorta o interlocutor a examinar determinado conceito, a buscar conhecer o bem e a verdade, a tornar-se melhor. Utiliza-se então de argumentação para testar a veracidade, coerência e conhecimento de seu oponente. A "refutação" das ideias do interlocutor tem a função de fazê-lo reconhecer as falhas do próprio pensamento, sua ignorância, para em seguida encaminhá-lo à descoberta da verdade. Purificado do erro, das inconsistências de um saber aparente, o interlocutor é conduzido à etapa seguinte. A maiêutica é uma investigação na qual o interrogado busca a verdade dentro de si mesmo através da coerência lógica.

Para Mondolfo, "a interrogação verdadeira do verdadeiro mestre é na realidade um método de ensino e de instrução, mas de uma instrução ativa que se exerce sem que o pareça, como estímulo, guia e sugestão disfarçada" (MONDOLFO, 1972, p. 59). Percebe-se a maestria de Sócrates ao conduzir o interlocutor através de perguntas e argumentos, da simples opinião ao desenvolvimento do pensamento crítico que lhe permite descobrir um saber que traz em si mesmo, mas que até então ignorava. Isso implica a capacidade de reco-

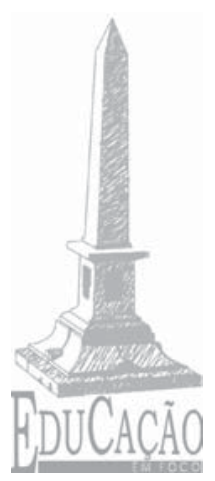

69 
nhecer as formas inválidas de argumentação para que as falsas conclusões sejam eliminadas, expurgadas, ou seja, refutadas.

Para que a refutação seja eficaz, é necessário, portanto, eliminar as falácias. Isso é o que sugere o tema desta pesquisa: quais são os tipos de argumentos inválidos que os alunos pesquisados são capazes de perceber? Parte-se da hipótese de que eles não compreendem regras mais elaboradas do pensamento analítico e da dialética, mas é difícil determinar a priori a linha de demarcação entre o que seriam capazes de perceber ou não.

Como instrumento auxiliar na tarefa de detecção de inferências falsas, Sagan sugere um "kit de ferramentas" para exercitar o pensamento crítico. Ele o define como um:

meio de construir e compreender um argumento racional e - o que é especialmente importante - de reconhecer um argumento falacioso ou fraudulento. A questão não é se gostamos da conclusão que emerge de uma cadeia de raciocínio, mas se a conclusão deriva da premissa ou do ponto de partida e se essa premissa é verdadeira (SAGAN, 2007, p. 241).

Sagan apresenta inúmeros exemplos de falácias muito comuns e de domínio público e encerra o capítulo Sobre a arte refinada de detectar mentiras afirmando "que é, em parte, por causa da falta disseminada de conhecimento sobre a detecção de mentiras que a indústria e a mídia enganam e a credulidade mata" (SAGAN, 2007, p. 252).

Marcelo Dascal, professor da universidade de Tel-Aviv, enfatiza a importância da dialética em um artigo intitulado "A importância da dialética na construção coletiva do saber científico" (DASCAL, 2005). Ele lembra, contudo, que isso talvez somente seja possível através do confronto crítico entre abordagens, projetos, metodologias, objetivos, disciplinas, teorias e cientistas individuais ou grupos de cientistas. Ele mostra, historicamente, como é complexa essa discussão entre "coletivo" e "público" e afirma que isso leva à reflexão sobre o papel do conflito e do diálogo na construção da ciência, 70 "desde a elaboração de critérios, das tomadas de decisão até as im- 
plicações de seus resultados" (DASCAL, 2005, p. 17). Ele lembra Popper que diz: "sem contradições, sem criticismo, não haveria motivação racional para mudarmos nossas teorias: não haveria progresso intelectual" (POPPER, 1963 apud DASCAL, 2005, p. 17).

Particularmente, no tocante à atividade do professor em sala de aula, é útil recordar Lipman:

[...] fornecer incentivos que motivem os alunos a se aplicarem na atividade científica e proporcionar um conjunto de hábitos de trabalho que combine com suas inclinações criativas e imaginativas, com seus próprios desejos de pensar de uma maneira disciplinada e ordenada a respeito do mundo (LIPMAN, 1994, p. 54).

\section{Metodologia}

A motivação para a presente pesquisa parte dos seguintes pressupostos:

a) o debate é uma construção complexa e fundamental para a apresentação das próprias ideias e descobertas; e também para perceber ideias convergentes e divergentes no seu próprio discurso e no do seu oponente;

b) os professores devem utilizar esses recursos ao ensinar a natureza da ciência;

c) os professores e estudantes devem ter conhecimento de como os cientistas agem para alcançar suas conclusões e quais são suas limitações, pois é isso que permite a constante renovação das ciências.

$\mathrm{O}$ universo pesquisado envolve estudantes de graduação de duas faculdades públicas, uma turma da área de ciências exatas e outra de ciências humanas. Da turma de ciências exatas, participaram 20 estudantes, com predominância do sexo masculino. Da turma de ciências humanas, participaram 19 estudantes, dos quais 18 eram do sexo feminino. O questionário foi aplicado na presença dos professores das duas turmas.

O experimento consistiu da distribuição aos estudantes, para

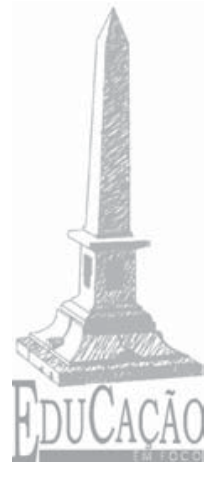

71 
leitura, de três textos, versando sobre temas científicos e seguidos de um questionário. Este visava identificar se os estudantes reconheceriam as falácias ali contidas e se saberiam argumentar sobre elas.

Ambas as turmas gastaram em média 20 minutos para responder e entregar o questionário juntamente com o termo de consentimento, assinado, para participar da pesquisa após ter-lhes sido exposta a proposta do trabalho e prestado o esclarecimento acerca do caráter voluntário de sua participação.

Um dos textos analisados intitula-se Por uma nova biologia, de Christiano P. da Silva Neto (2007), originalmente distribuído pelo autor, acompanhado de um convite para uma palestra, o qual afirma que seria sorteado um pen drive para a plateia. A escolha desse material, aparentemente um ensaio sobre biologia, deve-se ao fato de que ele consiste, em verdade, em uma apologia à teoria criacionista por meio de interpretação literal e extremamente parcial de uma das inúmeras versões da bíblia. Portanto, o "novo" que aparece no título refere-se a um texto de centenas de anos, fixado a partir de uma de suas diversas tradições orais e interpretado de forma literal segundo uma hermenêutica anacrônica, cujo maior mérito é o de reinstalar a discórdia e a celeuma entre áreas do saber apaziguadas há pelo menos um século. Ressalte-se que não se coloca em questão a veracidade ou aceitabilidade dessa teoria, mas apenas a validade dos argumentos empregados pelo autor.

Silva Neto explora o desconhecimento generalizado dos padrões de conduta da ciência. Segundo Wenning, quando as pessoas sabem como os cientistas agem e alcançam suas conclusões científicas e quais são as limitações de tais conclusões, pensam melhor sobre o que está sendo dito pelo cientista e não rejeitam suas conclusões imediatamente, nem as aceitam sem crítica. A mídia está repleta de pessoas fazendo afirmações e suposições sobre várias coisas, algumas com fundamento, outras não. Então, um estudante que possui um bom entendimento do conteúdo da natureza da ciência terá supostamente maior facilidade em distinguir evidência de propaganda, possibilidade de certeza, crenças racionais 
de superstições, ciência de folclore, teoria de dogma.

A análise dos argumentos usados no texto será realizada com base na Dialética Erística de Schopenhauer elaborada provavelmente no fim de seu período berlinense, entre 1830-31, e publicada postumamente. Trata-se de uma compilação de 38 estratagemas, os artifícios desonestos mais recorrentes nas controvérsias, com exemplos ilustrativos. A erística constitui um verdadeiro manual para defender-se dessas simulações, muito frequentes em obras pseudocientíficas. Os argumentos falaciosos serão identificados por meio da comparação do conteúdo do texto distribuído aos estudantes com a descrição dos estratagemas fornecida na erística. Neste estudo, serão mencionados apenas os estratagemas efetivamente observados durante o experimento, identificados pela letra E acompanhada por um número, que corresponde à classificação do próprio Schopenhauer, e pela denominação, entre parênteses, com que são usualmente conhecidos.

\section{Resultados e discussão}

O texto Por uma nova biologia tem como ponto de partida o estratagema E 13 (alternativa forçada). O E13 consiste em apresentar a tese contrária à que se defende, ressaltando a oposição com "estridência" e deixando que o ouvinte escolha. Esse modo de apresentação faz com que ele tenha que se decidir pela tese que, em comparação à outra, mostra-se muito mais provável. Se não quiser ser contraditório, ele é forçado a optar por uma das alternativas. Por exemplo, na seção intitulada Criação X evolução, são realçados com "estridência" os pontos que ele considera negativos na teoria da evolução: "o macaco não tem culpa de tudo que acontece de errado no mundo" ou "a teoria da evolução contraria também pressupostos filosóficos e científicos construídos pela humanidade" ou ainda "os evolucionistas preferem manter-se alheios ao debate".

Vale lembrar que a teoria de Darwin aparece em um contexto histórico, sem a preocupação de explicar o homem, especificamen-

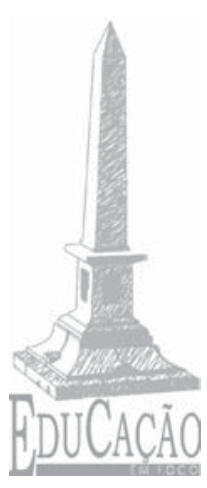

73 
te sua intenção é investigar toda a vida, a possível evolução das espécies de todos os seres vivos.

O E4 (pré-silogismo) permeia todo o texto, pois seu objetivo é evitar que o leitor ou o ouvinte perceba claramente a que conclusão quer chegar. Para tal, ele coloca, aos poucos e de modo disperso, algumas premissas sem uma ordem aparente, ocultando o jogo, com a finalidade de induzir o leitor a aceitar a conclusão que será exposta no fim, como modo de manipulação da opinião pública.

Outro estratagema que aparece com frequência é o E5 (uso intencional de premissas falsas). Aqui ele utiliza afirmações de conhecimento de domínio público, mas sem o aprofundamento necessário que permitiria a reflexão e a réplica. Já no parágrafo inicial faz afirmação equivocada: "a evolução é um fato e não uma tese, ensinam”. Sabe-se que é justamente o oposto: a teoria da evolução é uma tese, uma tese científica baseada em evidências, e não um fato. Outro exemplo: "há um conjunto de provas rigorosamente científicas a demonstrar que o homem jamais compartilhou com o macaco um ancestral comum". Ora, negar o efeito não implica negar a causa. Ele afirma que não foram encontrados fósseis que façam os cientistas manterem o interesse na continuação da investigação. Isso é uma falácia, pois já foram encontrados, em abundância, animais intermediários entre espécies, como dinossauros e mamutes.

Um exemplo combinado de E4 e E5: " contra o Criacionismo move-se atualmente uma conspiração que tem o objetivo de lançarnos no completo descrédito" - uma afirmação de efeito, no início do segundo parágrafo, forçando ao uso do exagero da palavra "conspiração" enquanto deveria, se fosse coerente, argumentar com fatos, já que para ele os fatos é que seriam importantes e que deveriam apresentar os pontos fortes e fracos de cada teoria. No texto não aparece nenhuma apresentação de ponto fraco do Criacionismo, apenas afirmações vagas e genéricas tais como: "as pegadas deixadas na natureza favorecem o modo de pensar que se fia na figura do Criador. Nada há de concreto a embasar a teoria da evolução". Como se pode prever, não dirá quais seriam tais "pegadas", nem o 
que haveria de "concreto" no Criacionismo, prosseguirá apenas verberando, com estridência, o evolucionismo, bem ao estilo dos pré-silogismos: afirmações falaciosas, genéricas, aleatórias.

Utiliza-se também do E3 (mudança de modo), usando o que é apresentado de modo relativo como se fosse absoluto, induzindo a uma "compreensão" de sentido diferente, como na seguinte afirmação: "e note-se que nunca se escavou tanto no mundo como nos últimos 100 anos e o máximo que darwinistas encontraram para sustentar sua teoria foram peças fragmentárias como restos de fêmures e mandíbulas" - alegação falsa como foi dito no início desta análise.

É interessante notar como se aliam a esses estratagemas também o E1 (ampliação indevida) e o E12 (manipulação semântica), mudando inclusive o sentido do conceito de ciência:

O Criacionismo, por seu lado, não desafia tais pressupostos e procura se ater às evidências verdadeiramente científicas [...] algo assim como se de um ovo de serpente brotasse de repente um pássaro emplumado. Pergunto-me, e aos pais e professores, se já não está passando da hora de, num debate franco e aberto, colocar em dúvida este improvável método científico (SILVA NETO, 2007, p. 1).

Para concluir, observa-se ainda o uso do E32 (rótulo odioso), ao fazer afirmação que gera dúvida e possa levá-la à categoria de detestada: "convenhamos que pedaços de ossos são um alicerce muito frágil para se assentar sobre eles uma teoria que nega Deus", ou seja, fica explícito, de forma estridente, em seu texto, que darwinismo é sinônimo de negação de Deus - outra falácia.

É interessante observar como em um texto tão pequeno, de apenas uma página, foram detectados pelo menos sete estratagemas da Dialética Erística de Schopenhauer (E1, E3, E4, E5, E12, E13, E32), todos eles argumentos inválidos, mas adequados ao objetivo precípuo de convencimento do leitor acerca do ponto de vista do autor.

Após o inventário das falácias encontradas, cabe analisar as respostas dos estudantes para determinar se foram capazes de percebê-

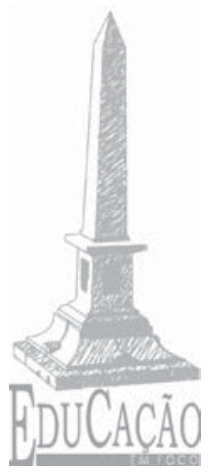

75 
las e em que medida revelaram-se susceptíveis a esse tipo de retórica.

\section{Respostas da turma de ciências exatas}

Na turma de ciências exatas, todos os 20 estudantes responderam ao questionário e alguns fizeram perguntas, demonstrando curiosidade sobre o trabalho de pesquisa.

Sobre a pergunta número um (Justifique sua motivação para ir à palestra recebendo "este" convite), nenhum deles fez argumentação apropriada; 16 deram opiniões, fizeram comentários, e apenas quatro responderam com argumentos considerados pertinentes, porém superficiais, por exemplo: "eu não iria à palestra, porque não gostei da imagem do macaco dando aula" ou "eu iria à palestra para ganhar o pen drive" - a primeira página do texto é um convite para assistir à palestra sobre Criação X Evolução, com a promessa de sortear esse equipamento entre a plateia. Esses argumentos foram considerados pertinentes, porque explicitam motivações para ir ou não ao evento, e superficiais, porque não têm correlação com o tema supostamente científico que seria discutido. Apenas um estudante condenou a promessa do sorteio durante a palestra: "a necessidade do sorteio de um pen drive para atrair público põe em dúvida a qualidade desta".

Sobre a pergunta número dois (Qual a teoria que o autor defende?) todos os alunos responderam corretamente. Não foi solicitada justificativa/argumentação para a resposta.

Sobre a pergunta número três, solicitando aos estudantes que analisassem os argumentos apresentados pelo autor, nenhum deles fez argumentação apropriada; 16 deram opiniões, fizeram comentários, e apenas quatro responderam com argumentos superficiais, ou seja, sem correlação com os argumentos apresentados no texto.

Sobre a pergunta número quatro, (Em relação à teoria defendida pelo autor, você concorda? Não concorda? Por quê?), nenhum deles fez argumentação apropriada; 15 deram opiniões ou fizeram comen76 tários e apenas cinco responderam com argumentos superficiais. 


\section{Respostas da turma de ciências humanas}

Na turma de ciências humanas, todos responderam, mas apenas duas alunas tiveram curiosidade de saber mais sobre o trabalho de pesquisa.

Sobre a pergunta número um (Justifique sua motivação para ir à palestra recebendo "este" convite), nenhum deles fez argumentação apropriada; 16 deram opiniões, fizeram comentários, e apenas três responderam com argumentos pertinentes, mas superficiais. Dois estudantes se referiram ao pen drive exposto na primeira página do texto, o convite para assistir à palestra sobre Criação X Evolução. Um disse que iria para ganhar o pen drive e outro disse que o autor não deveria acreditar no que falaria, já que tinha que usar um pen drive para atrair pessoas para assistir à sua palestra. No geral, as respostas foram vagas, alguns fizeram mera cópia de frases do autor, sem nem mesmo comentá-las. Dois estudantes se referiram à figura do macaco, um achando estimulador, outro dizendo que o macaco certamente seria ele, o autor.

Sobre a pergunta número dois (Qual a teoria que o autor defende?), todos responderam corretamente. Não foi solicitada justificativa/argumentação para a resposta.

Sobre a pergunta número três, solicitando aos estudantes que analisassem os argumentos apresentados, nenhum deles fez argumentação apropriada; 16 deram opiniões, fizeram comentários, e apenas três responderam com argumentos "superficiais".

Sobre a pergunta número quatro (Em relação à teoria defendida pelo autor, você concorda? Não concorda? Por quê?), nenhum fez argumentação apropriada; 18 deram opiniões, fizeram comentários, e apenas um respondeu com argumentos superficiais.

Apenas um estudante de cada turma, o equivalente a $5 \%$, percebeu a intenção de manipulação envolvida na oferta de sorteio do pen drive entre aqueles que assistissem à palestra. Nenhum estudante das duas turmas detectou o uso de falácias, de argumentos

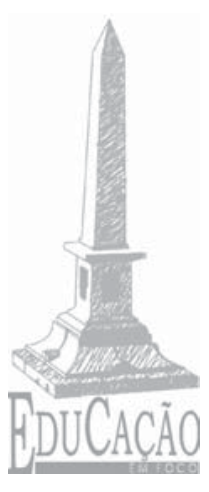

77 
enganosos. Poucos estudantes, menos de $20 \%$, manifestaram algum desconforto com relação ao estilo de argumentação empregado. Porém, não se pode afirmar que esses tivessem consciência das falácias, pois não souberam explicitá-las formalmente. Trata-se mais de um incômodo, uma intuição de que algo esteja errado devido a expressões do tipo há "exagero do autor", "ele é inseguro e quer chamar atenção sorteando pen drive", "ele é o macaco que está no convite". Não obstante, todos os estudantes foram capazes de entender a tese defendida no texto e de acompanhar a linha de argumentação empregada, ou seja, eles não têm problemas de compreensão.

Os resultados obtidos refletem o tipo de ensino ministrado aos estudantes. Eles são preparados para acompanhar o discurso corretamente elaborado e as demonstrações matemáticas necessárias, mas não para questionar, discordar, nem para expor as contradições e as falhas cometidas pelo interlocutor, como fazia Sócrates. Ora, o conhecimento científico sistematizado nos planos de ensino deriva de um trabalho coletivo, construído ao longo de séculos por meio de debates e solução de polêmicas. Longe de ser aceito de imediato como uma verdade autoevidente, o conhecimento científico é permanentemente submetido a questionamentos, muitas vezes por defensores de teorias alternativas. Como defende Dascal, provavelmente essa é uma condição necessária para sua existência, ou seja, o confronto crítico entre abordagens, projetos, metodologias, objetivos, disciplinas, teorias e cientistas individuais ou grupos de cientistas. Não por acaso, é o procedimento habitual observado nos grupos de pesquisa, em defesas de teses e dissertações acadêmicas, em congressos e simpósios, no processo de publicação em periódicos especializados.

Para realizar bem essa tarefa, é necessário conhecer as formas válidas e muito útil conhecer as formas inválidas de argumentação. As duas formas deveriam ser discutidas e ensinadas na escola. Esse conhecimento é necessário para iluminar o caminho da pesquisa e útil para ajudar aquele que não sabe, mas pensa que sabe, reconhecer o próprio erro, como também para defenderse dos falsos sábios (sofistas) que se valem da ignorância genera78 lizada para divulgar e promover a pseudociência.

Ano 12 - n. 14 - dezembro 2009 - p. 67-81 


\section{Conclusão}

Os dados apresentados corroboram a hipótese de partida desta pesquisa e leva a pensar no que Carl Wenning diz sobre a necessidade de preparar melhor os professores, porque, se os alunos não conseguem detectar argumentos falaciosos e capciosos, mesmo em um texto simples sobre ciências, é porque não aprenderam com seus professores a pensar bem, de modo apropriado para compreender o processo de construção do conhecimento.

Nesta pesquisa também ficou claro que os alunos não reconhecem os procedimentos, as jogadas e seus lucros cognitivos, colocados pelo autor do texto analisado. A dialética, sobretudo a que se manifesta nas controvérsias, desempenha importante papel na construção coletiva do conhecimento científico; e a ciência é uma construção coletiva.

Essas afirmações de pesquisadores/autores remetem à ideia de que desenvolvimento e progresso são interligados e indissociáveis da ideia de construção do conhecimento. As questões ligadas à ciência e à tecnologia remetem-nos também à Escola de Frankfurt, ao esforço dos epistemólogos modernos e contemporâneos para despertar a consciência do sujeito que elabora discursos. Suas reflexões mostram como o pensamento de Sócrates e de Schopenhauer são atuais e, se utilizados de modo didaticamente apropriados, podem ajudar alunos e professores na construção de um modelo de ensino de ciências mais inteligente e eficaz na relação teoria-prática.

A maior contribuição deste trabalho é mostrar que também a erística pode ser usada como forma de preparação para entender o processo de pesquisa e do discurso científico, a detecção das falhas de pensamento, o reconhecimento das falácias e argumentos capciosos, e não apenas como é geralmente conhecida, ou seja, uma arte de disputar por meios lícitos ou ilícitos para sempre ter razão.

\section{Agradecimentos}

A Fapemig pelo fomento e confiança na relevância desta pesquisa.

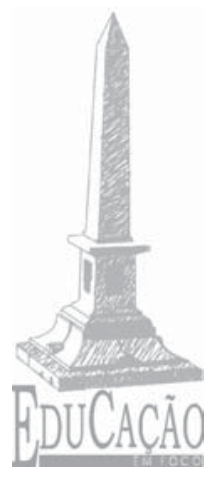

79 


\section{Referências}

DASCAL, M. A dialética na construção coletiva do saber científico. In: REGNER, A. C.; ROHDEN, L (Org.). A filosofia e a ciência redesenham horizontes. São Leopoldo: Unisinos, 2005.

JAEGER, W. Paidéia. São Paulo: Martins Fontes, 2003.

LIPMAN, M. A filosofia na sala de aula. São Paulo: Nova Alexandria, 1994.

. A filosofia vai à escola. São Paulo: Summus, 1990.

. O pensar na educação. Petrópolis: Vozes, 1995.

MONDOLFO, R. Sócrates. São Paulo: Mestre Jou, 1972.

PLATÃO. Teeteto. In:___ _ Diálogos I. Bauru: Edipro, 2007.

SAGAN, C. B. O mundo assombrado pelos demônios. São Paulo: Cia. das Letras, 2007.

SILVA NETO, C. P. da. Por uma nova biologia. Revista Universo em Debate, n. 1, v.1, 2007.

SCHOPENHAUER, A. A arte de ter razão. São Paulo: Martins Fontes, 2005.

YIN, R. K. Estudo de caso: planejamento e métodos. Porto Alegre: Bookman, 2010.

WENNING, C. J. Engaging students in conducting socratic dialogues: suggestions for science teachers. Illinois: University of Illinois, 2006. 


\title{
Erístic in science education
}

\begin{abstract}
This research investigates the skills of higher education students to recognize fallacious arguments, detecting invalid assertions presented in pseudo-scientific texts, and understand the process of construction of science as something rich and creative, beyond mere conclusions found in textbooks. The research methodology is based on case study, involving students of exact sciences and humanities. As a result, no student was able to detect invalid stratagems contained in a pseudo-scientific text, although some of them perceived some exaggerations, and it is recommended to combine the teaching of philosophy with science, particularly the use of Eristic of Schopenhauer, as a way to develop into students the skill to recognize fallacious arguments.
\end{abstract}

Keywords: Eristic; science education; maieutic.

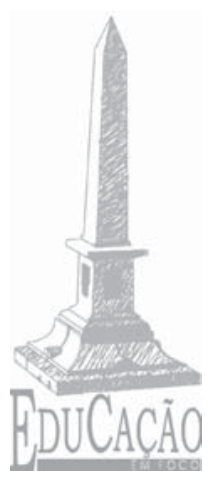

81 